\title{
Treatment Decision Using Analytic Hierarchy Process (AHP) Based Framework
}

Krishna Sharma, MS

Neurosurgeon

B\&B Hospital, Gwarko, Lalitpur, Nepal.

krishnasharma@yahoo.com

\author{
Shashi Bhattarai, MA \\ Development Dynamics Pvt. Ltd. \\ Kathmandu, Nepal
}

\author{
Address for correspondence: \\ Neurosurgeon \\ B\&B Hospital, Gwarko, Lalitpur, Nepal. \\ Email: krishnasharma@yahoo.com
}

Received, 10 December, 2011

Accepted, 21 December, 2011
Medical decision on treatment is a complex process and requires in-depth analysis of conflicting variables which may not only be medical but also could be financial or social considerations. At times, in making the decisions, a doctor pass through a very difficult time in deciding on which type of treatment would give a patient the best result under a certain circumstances. The decision would be made based on the doctor's knowledge, experience, scientific data available, patient's clinical, social, financial states and many other factors. The end result may not be as expected as it too may depend on many other factors. The treating physician would always be in a dilemma about the correctness of his decision and would have no objective way of knowing it. To justify one's decision to oneself, the patient and his relatives and at times in the court of Law is always difficult. The Analytic Hierarchy Process (AHP) which was developed by Saaty ${ }^{10,11}$ and studied extensively by many analysts ${ }^{5,9,12}$ is one of the best known and most widely used MCA approaches. Analytic Hierarchy Process (AHP) based framework is a method of analysis of the variables influencing the treatment a patient under some circumstances and comes up with the best possible line of treatment. The process has been in use for more than thirty five years since is inception in $1977^{10}$ in many types of decision making, both health related ${ }^{9}$ and not related. AHP has found it application in many health related areas like Monitoring Healthcare Performance ${ }^{1}$, Breast cancer ${ }^{2}$, Selecting medical devices ${ }^{3}$, colorectal cancer screening ${ }^{4}$, choice of initial antimicrobial therapy ${ }^{6}$, measuring and comparing the global performance of intensive care units ${ }^{7}$, Selecting medical devices, ${ }^{8}$ and even the selection of surgery residents. ${ }^{13}$ An effort is made to illustrate this idea in neurosurgical practice by analyzing a case of cervical injury retrospectively.
$\mathrm{M}$ aking decision in the management of Neurosurgical patients is determined by many variables. In addition to the pure clinical variables like pathology, clinical presentation, duration, progression of the disease, age etc, there are lots of other non-clinical factors that influence the decision. The non-clinical factors could be like economic condition, care takers at home, availability of rehabilitation facilities, likely would of the patient coming for follow up or not and many others.
Despite all these variables, the decision may have to be taken quickly, alone and without having the opportunity to take opinion of other experts. The evaluation of the decision, whether it was correct or not, can only be made retrospectively after a definitive result is obtained, good or bad, which could be a day or years after the decision was made. Meanwhile the treating physician may have many sleepless nights and tension. The presently flourishing medico-legal problems have further demanded an objective 


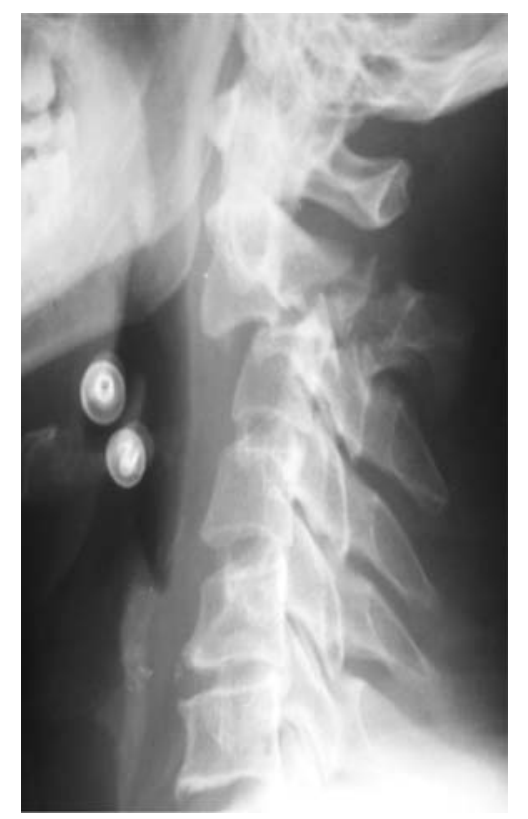

Figure 1: X-ray C 2-3 fracture subluxation

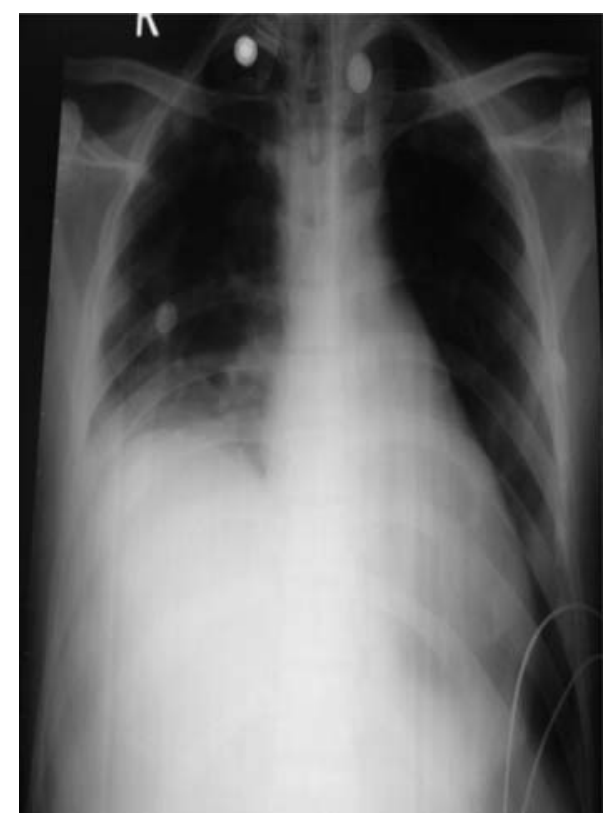

Figure 2: X-ray high dome of diaphragm on right side

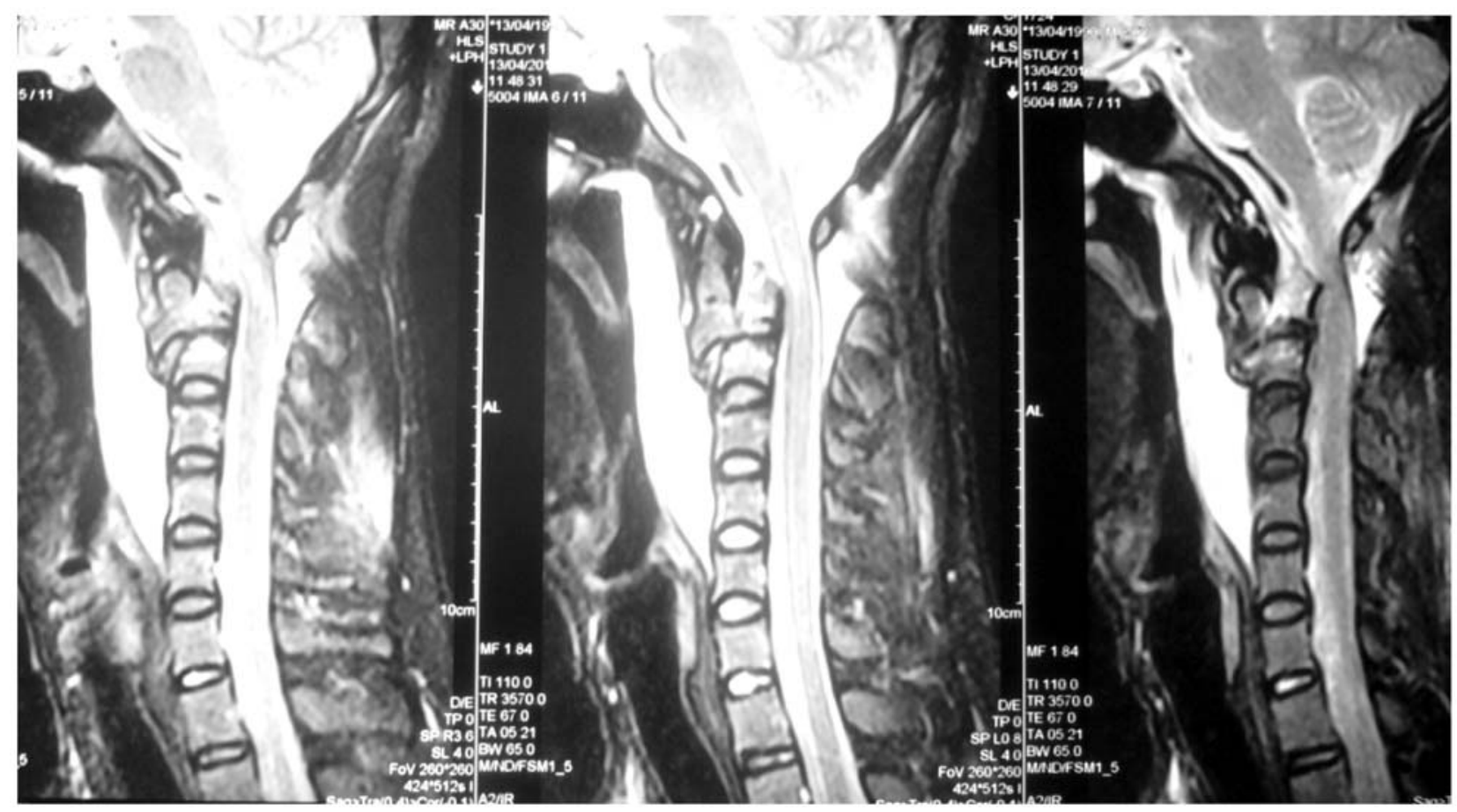

Figure 3: MRI Fracture subluxation of C 2-3 with cord compression, contusion, prevertebral haematoma and other soft tissue injuries.

decision making armamentarium amidst so many subjective variables influencing the decision making of the treatment in a patient. The treating doctor also needs to know, otherwise also, whether the decision taken on the course of treatment was appropriate for the patient, supported by the knowledge, experience and the scientific data available.
Thus a concept of Analytic Hierarchy Process (AHP) has been developed which processes the important variables influencing the treatment of a patient and comes out with the best possible course of treatment. The treating doctor decides on how much one variable is important compared to the other variable in percentage. It takes into account 


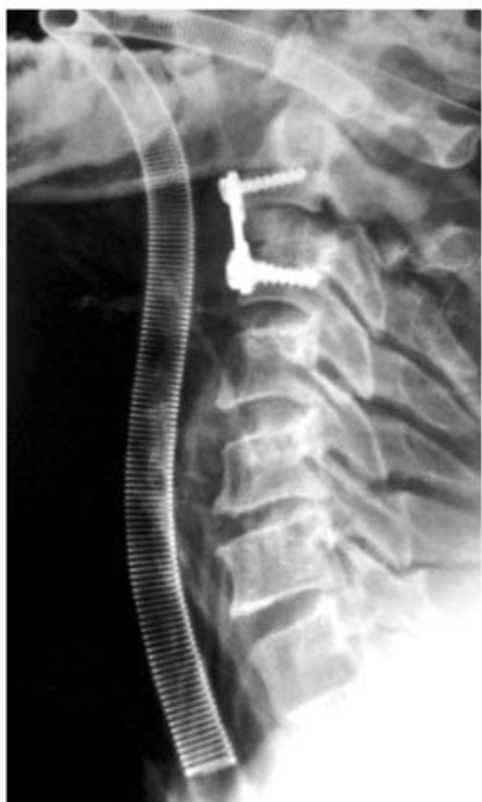

Figure 4: X-ray postoperative picture with reduced, fused and fixed C 2-3 subluxation

decision making armamentarium amidst so many subjective variables influencing the decision making of the treatment in a patient. The treating doctor also needs to know, otherwise also, whether the decision taken on the course of treatment was appropriate for the patient, supported by the knowledge, experience and the scientific data available. Thus a concept of Analytic Hierarchy Process (AHP) has been developed which processes the important variables influencing the treatment of a patient and comes out with the best possible course of treatment. The treating doctor decides on how much one variable is important compared to the other variable in percentage. It takes into account and analyses every single of the variables supplied by the physician, pair-wise compares importance of each variable and finally gives the most appropriate line of treatment.

\section{Case Discussion}

A 20-year-old boy from a remote village in eastern hills of Nepal with a very poor economic status, presented in the emergency department two hours after sustaining injuries to the neck on rehearsing stunts for a film. Immediately following the injury he had severe neck pain, was unable to move any of his limbs, had difficulty in breathing and had not passed urine till he presented to the emergency department.

On arrival, he had pulse of 52/minute, blood pressure of $90 / 60$, respiration was 33/minute, shallow, laboured and abdominal only. The oxygen saturation was $86 \%$. His level of consciousness was normal (GCS 15/15). There was crepts all over the chest with intense conducted sounds. He had flaccid quadriplegia with absent sensation below clavicle. The deep tendon reflexes were absent.

His neck was stabilized on a Philadelphia collar and was resuscitated. Respiratory pattern remained abdominal, labored and oxygen saturation did not improve beyond $92 \%$. He was further investigated. X-ray showed C2-3 fracture subluxation. X-ray chest showed high lying dome of diaphragm on the right side suggesting high cervical cord injury with phrenic nerve palsy. MRI of cervical spine showed C2-3 fracture subluxation with evidence of cervical cord contusion at $\mathrm{C} 2$ level. Other required investigations were within the normal limits.

\section{Patient's Medical Scenario Coupled with Socio-economic Condition}

This was a young man from a very poor family of the eastern hills of Nepal and had sustained a high cervical cord injury with flaccid quadriplegia and respiratory insufficiency. With MRI findings of the cord compression and contusion, the chance of the recovery of the limbs was very minimal. One of the most important short term prognostic factors was his inability to breathe adequately, cough out sputum and protect his airway. Even if the patient made sustainable improvement, the treatment would take a long time and was very expensive. Even then the result would most likely be a severely disabled individual. To conclude the list of the problem, the cost of the treatment had to be paid by the family itself which was very difficult.

\section{Scenario Based Options Considered}

Considering the above scenario, the treatment options considered under the circumstances were:

a. Leave him alone and let the nature take its course: The reason was that the patient came from a poor family and the family would have to bear the whole cost of treatment which will drain all the resources of his family whatever little they have making it difficult for the rest of the family members to survive.

b. Do the treatment aggressively as per the books and literature guides: Apply cervical traction, start Injection Methylprednisolone (US\$ 350), prepare and perform surgery (cervical discectomy, fusion and fixation US\$ 6,850). Postoperatively he would need ICU care, tracheostomy and medicines including expensive antibiotics for the chest infection which he was bound to develop.

c. The middle path was to go step by step: watching the condition of the patient, financial and moral support of the family and development of the complications.

\section{The Option Opted and the Course of Action}

The medical doctor opted for the third option described 
above, along with the following medical management process. A movie company agreed to help him financially.

- He was not given methylprednisolone, the only steroid which has shown some benefit in spinal cord injury presenting within 8 hours. However it is very expensive with its own intrinsic complications which itself could lead to patient's death.

- Cervical traction was applied.

- Cervical discectomy, fusion and fixation were done.

- Postoperatively, he needed ICU care and ventilator support to maintain his oxygenation. Tracheostomy was done to facilitate tracheal toileting and reducing dead respiratory air passage. Sensitive, strong but very expensive antibiotics had to be used to control his chest infection.

- The attempts to wean him off the ventilator failed despite repeated attempts.

- The family and the helping agency gave up on the $7^{\text {th }}$ postoperative day and the ventilator was switched off after giving informed consent.

- The patient died soon after switching him off the ventilator from respiratory failure on the $7^{\text {th }}$ postoperative day.

The decision to choose a definite line of treatment

\begin{tabular}{|c|c|c|c|c|c|}
\hline \multirow{2}{*}{$\begin{array}{l}\text { Objective } \\
\text { Level } 1\end{array}$} & \multicolumn{4}{|l|}{ Factors } & \multirow{2}{*}{$\begin{array}{l}\text { Alternative course of } \\
\text { action } \\
\text { Level } 6\end{array}$} \\
\hline & Level 2 & Level 3 & Level4 & Level 5 & \\
\hline \multirow{2}{*}{$\begin{array}{l}\text { Evaluation } \\
\text { of }\end{array}$} & \multirow[t]{2}{*}{ Social } & \multicolumn{3}{|l|}{ Long Term } & \multirow{3}{*}{ Nature take the course } \\
\hline & & \multicolumn{3}{|l|}{ Short Term } & \\
\hline$C_{0}$ & & \multirow{3}{*}{ Investigation } & \multicolumn{2}{|l|}{ Blood } & \\
\hline \multirow{2}{*}{ Action } & & & & Bone & \multirow{4}{*}{ Aggressive treatment } \\
\hline & & & $\begin{array}{l}X-R a y, C T \text { Scan, } \\
\text { MRI }\end{array}$ & $\begin{array}{l}\text { Soft } \\
\text { Tissue }\end{array}$ & \\
\hline \multirow{5}{*}{$\begin{array}{l}\text { Patient } \\
\text { Treatment }\end{array}$} & & & Fitness & & \\
\hline & & ratumt & Consent & & \\
\hline & & & Clinical Conditio & & \multirow{3}{*}{ Step by step treatment } \\
\hline & \multirow[t]{2}{*}{ Financial } & \multicolumn{3}{|l|}{ Immediate } & \\
\hline & & \multicolumn{3}{|l|}{ Future } & \\
\hline
\end{tabular}

Table 1: The patient treatment decision evaluation framework. 


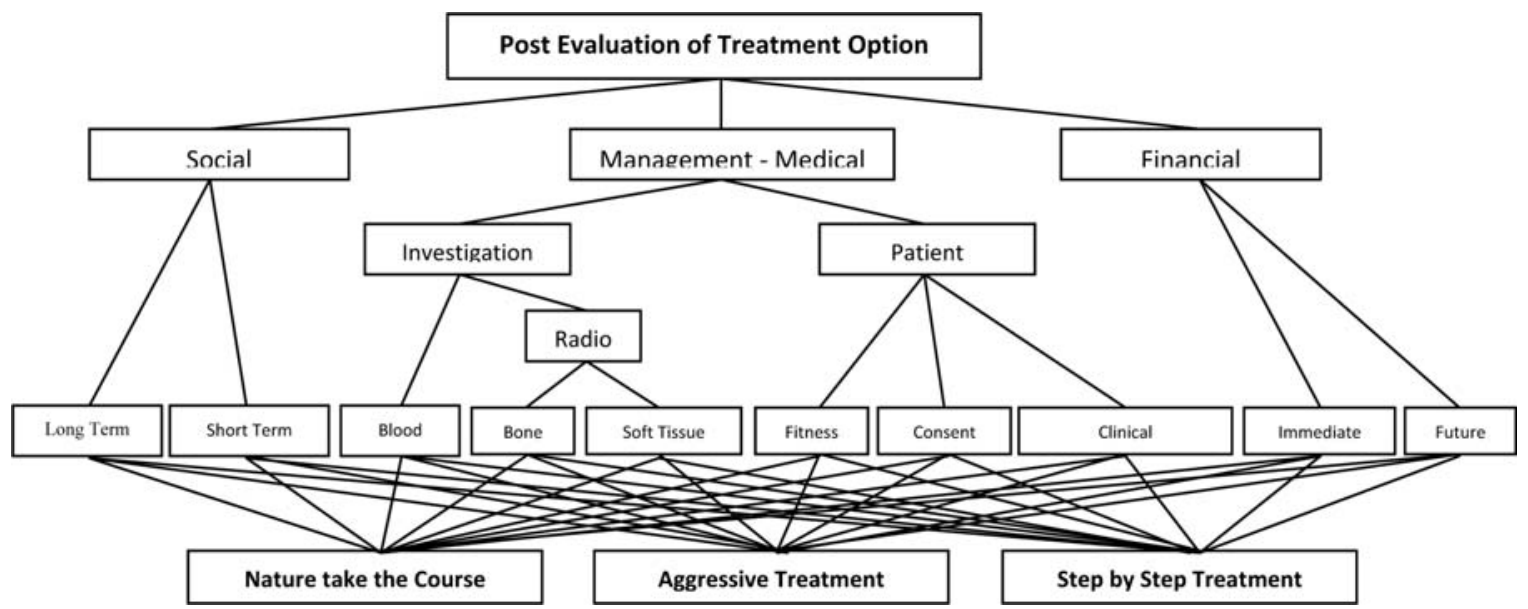

Figure 5: AHP Framework for Post Medical decision Evaluation

\begin{tabular}{|c|c|c|c|c|}
\hline \multicolumn{5}{|c|}{ Weights Generated } \\
\hline Factors & Criteria & Sub-criteria & Sub-subcriteria & Ranking of Alternatives \\
\hline \multirow{2}{*}{$\begin{array}{l}\text { Social } \\
(0.164)\end{array}$} & \multicolumn{3}{|c|}{ Long Term (0.072) } & \multirow{3}{*}{ Nature take the course } \\
\hline & \multicolumn{3}{|c|}{ Short Term (0.092) } & \\
\hline \multirow{6}{*}{$\begin{array}{l}\text { Management } \\
(0.476)\end{array}$} & \multirow{3}{*}{$\begin{array}{l}\text { Investigatio } \\
\mathrm{n}(0.238)\end{array}$} & \multicolumn{2}{|l|}{ Blood (0.058) } & \\
\hline & & Radiological & Bone $(0.118)$ & \multirow{4}{*}{ Aggressive treatment } \\
\hline & & & Soft Tissue (0.062) & \\
\hline & \multirow{3}{*}{$\begin{array}{l}\text { Patient } \\
(0.238)\end{array}$} & \multicolumn{2}{|c|}{ Fitness (0.096) } & \\
\hline & & \multicolumn{2}{|c|}{ Consent $(0.057)$} & \\
\hline & & \multicolumn{2}{|c|}{ Clinical Condition $(0.091)$} & \multirow{3}{*}{$\begin{array}{l}\text { Step by step treatment } \\
(0.423)\end{array}$} \\
\hline \multirow{2}{*}{$\begin{array}{l}\text { Financial } \\
(0.360)\end{array}$} & \multicolumn{3}{|c|}{ Immediate (0.209) } & \\
\hline & \multicolumn{3}{|c|}{ Future $(0.150)$} & \\
\hline
\end{tabular}

Table 2: Results of pair-wise comparison sessions 
was very difficult and considering all the variables influencing the treatment, it had been decided to operate the patient. However the treatment had to be discontinued and the patient died draining a lot of resources. The surgeon would always be in a dilemma and would never be sure if ever his decision was correct.

To have the insight on this issue and to have objective evaluation in such other patients, post evaluation of the decision on treatment was conducted using the Analytic Hierarchy Process (AHP). ${ }^{11}$ The AHP based decision hierarchy was prepared jointly with the surgeon and the decision analyst to map the decision scenario with factors considered earlier by the doctor. Initially all the decision factors under consideration were listed and then the factors were grouped to form the decision hierarchy in accordance to the AHP application practice. The decision framework, pair-wise comparison of decision factors, initial outcome and sensitivity analysis of the decision problem is presented in the paper.

\section{Decision Evaluation Framework}

Course of action for the treatment of the patient was post evaluated by using six level hierarchies as presented in the Table 1 and Figure 1. The decision hierarchy was mapped including all the conflicting decision variables as considered by the surgeon. The factors used in the decision hierarchy are defined briefly as follows:

Social: The social condition of the patient is mainly the availability of support to take care, network of relatives and friends. The social factor was further sub divided into long-term and short term social support availability and implication to patient and his family.

Management: This criterion was the major concern. The management factor was further divided into two parts, namely Investigation and Patient factors. Investigation factor consisted of Radiological findings and Blood investigation results. Radiological investigation factor was further divided into Bone and Soft Tissue investigation results. The other main factor under the investigation was Patient factor represented by the Physical Fitness, Clinical Condition of the patient, etc.

Financial: Under the financial criteria, two factors were considered, the Immediate and Future financial considerations relating to financial resource needed for the treatment and financial implication to family of the patient.

The six level decision evaluation framework consisting of three main factors, namely Social, Management (medical) and Financial. All together sixteen factors constituted the evaluation framework, out of which six (three each under social and financial) factors were non medical and rest ten factors are in relation to the medical management to decide the alternative course of action for the treatment of the patient.

\section{Assessment of Alternative Course of Medical Action}

Based on the post medical decision evaluation framework discussed above, an AHP based computer software was used for further process of evaluation. Sessions of pair wise comparisons were conducted by AHP application expert involving the medical doctor as a decision

\section{Importance to Factors}

\begin{tabular}{|l|}
\hline $16.4 \%$ Social \\
\hline 47.6\% Hgmt \\
\hline $36.0 \%$ Fincial \\
\hline
\end{tabular}

Synthesis

\section{9\% Natural}

\section{8\% AgrsTrea}

42.3\% StepStep

Figure 6: Outcome of decision evaluation in AHP framework 


\section{$10.0 \%$ Social}

\section{0\% Mgmt}

\section{0\% Fincial}

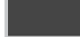

Synthesis of changed importance to factors

\section{$15.4 \%$ Natural}

\section{8\% AgrsTrea}

\section{$40.8 \%$ StepStep}

maker. The sessions of pair-wise comparison among the decision factors were conducted very carefully following the guidelines given in the AHP literature. ${ }^{10}$ The environment of pair-wise comparison was duly created so that the medical doctor could reflect his professional judgment made actually during the initial decision to arrive the course of action taken. Table 2 presents the priority weights generated after the pair-wise comparison sessions.

Graphically the result of the post medical decision evaluation is presented in Figure 2. The result represents as synthesis of evaluation giving the priority ranking of the treatment option.

Further the sensitivity analysis was conducted to see "what if" scenario and to identify the governing factor to arrive at the selected option of treatment. The sensitivity analysis also helped to the doctor get the insights of the medical decision evaluation process. The sensitivity was conducted by reducing the Importance of Social factor to $10 \%$ from $16.4 \%$, the financial factor was reduced to $5 \%$ from $36.0 \%$ and much of the importance was given to Medical management factor i.e. $85 \%$ increased from $37.8 \%$. The result of sensitivity analysis is presented in Figure 3.

\section{Results and Discussion}

The result of the AHP based analysis gets highest rank to the Step by step treatment process, which was actually adopted for the treatment of the patient. The step by step treatment alternative adopted was out-weighted by 4.5 percent than the aggressive treatment option. The sensitivity analysis showed that, if importance to the management factor was increased, the aggressive treatment options came to the first priority, showing the treatment option adopted was tread-off with the social and financial factor.

The result justified that with the given financial and social situation of the patient; the treatment option adopted was a rational decision; however the outcome of the adopted decision was not positive. It was also evident that, if somehow financial and social limitations were overcome, the treatment option would be "Aggressive" however positive outcome would still be uncertain.

The paper is an outcome of the joint effort of a neurosurgeon and a decision analyst for post evaluation of a management decision. The paper describes medical details of a neurosurgical situation, decision conditions, alternative course of actions available and decision taken in the given socio-economic condition. The post medical decision analysis using AHP framework was conducted to get insight of the medical decision problem to evaluate the rationality of the decision taken. The result of the decision analysis justifies the rationality of the decision taken by medical doctor. The sensitivity analysis of the medical decision problem also justified that the social and financial condition of patient governs the treatment option and AHP could help to transparently demonstrate the fact. The paper also demonstrates the need of decision analyst to medical professionals working together on making informed critical decisions for the satisfaction of medical doctors as well as patient and his/her next to keens.

\section{Conclusions}

During the joint exercise of the medical decision evaluation, we have come to the following conclusion:

a. AHP based decision analysis on medical treatment option is observed as a strong tool to judge the 
rationality of medical decision taken.

b. Insights of AHP based decision evaluation are perceived to be wisdom to medical professionals.

c. AHP is a user-friendly technique that enables a decision maker to use subjective values and combine them with more objective data in an explicit, unbiased manner to come up with the best possible decision.

d. AHP would be basis for informed medical decisionmaking and maintaining decision memories for case handling in the future.

e. It has been observed that mapping of decision environment in AHP framework is quite compatible with medical doctors with given learning and judgment capacity within their profession.

f. AHP would give a treating physician a definitive confidence in treatment as it would be derived from scientific and objective data giving a due space for the treating doctors to decide how much a particular variable is important in the management.

g. It would definitely help in medico-legal circumstances to verify one's decision.

h. AHP has yet to obtain a legal approval to use its decision as the best objective option in the decision making.

\section{References}

1. Ahsan, MK and Bartlema J: Monitoring Healthcare Performance by Analytic Hierarchy Process: A Developing-country Perspective, International Transactions in Operational Research,
2004.ÊVolume 11 Issue 4, pp 465 - 478, 2004

2. Carter KJ, Ritchey NP, Castro F, et al: Analysis of three decision-making methods: a breast cancer patient as a model. Med Decis Making 19:49-57. PMID: 9917020, 1999

3. Cho KT, Kim SM: Selecting medical devices and materials for development in Korea: the analytic hierarchy process approach. Int J Health Plann Manage 18(2): 161-74, 2003

4. Dolan J, Frisina S: Randomized controlled trial of a patient decision aid for colorectal cancer screening. Med Decis Making 22:125-139, 2002

5. Dolan JG, Isselhardt BJ Jr, Cappuccio JD: The analytic hierarchy process in medical decision making: a tutorial. Med Decis Making 9:40-50, 1989

6. Dolan JG: Medical decision making using the analytic hierarchy process: choice of initial antimicrobial therapy for acute pyelonephritis. Med Decis Making 9:51-6, 1989

7. Hariharan S, Dey P, Chen D: Application of analytic hierarchy process for measuring and comparing the global performance of intensive care units. J Crit Care 20:117-124, 2005

8. Keun-Tae CT, Kim SM. Selecting medical devices and materials for development in Korea: the analytic hierarchy process approach. The International Journal of Health Planning and Management 18: 161 - 174, 2003 Liberatore MJ, Robert L: The Analytic Hierarchy Process in Medical and Health Care Decision Making: A Literature Review. European Journal of Operational Research 189:194207, 2008

9. Saaty TL: A scaling method for priorities in hierarchical 